\title{
Optimum Condition of Ecologic Feed Fermentation by Pleurotus Ostreatus Using Soybean Curd Residue as Raw Materials
}

\author{
Min Shi (Corresponding author) \\ Graduate School of Life and Environmental Sciences, University of Tsukuba \\ 1-1-1 Tennodai, Tsukuba 305-8577, Ibaraki, Japan \\ Tel: 81-29-853-6972Ｅ-mail: shimin0816@gmail.com
}

Yingnan Yang

Graduate School of Life and Environmental Sciences, University of Tsukuba

1-1-1 Tennodai, Tsukuba 305-8577, Ibaraki, Japan

Tel: 81-29-853-8830 E-mail: yo.innan.fu@u.tsukuba.ac.jp

Yiting Li

Graduate School of Life and Environmental Sciences, University of Tsukuba

1-1-1 Tennodai, Tsukuba 305-8577, Ibaraki, Japan

Tel: 81-29-853-6972Ｅ-mail: liyitingyoyo@hotmail.com

Yuepeng Wang

Biomedical Research Institute, Advanced Industrial Science and Technology

1-1-1 Higashi, Tsukuba 305-8566, Ibaraki, Japan

Tel: 81-29-861-6053 E-mail: ouetsuhou@hotmail.com

Zhenya Zhang

Graduate School of Life and Environmental Sciences, University of Tsukuba

1-1-1 Tennodai, Tsukuba 305-8577, Ibaraki, Japan

Tel: 81-29-853-4712Ｅ-mail: tyou6688@sakura.cc.tsukuba.ac.jp

Received: June 20, 2011 Accepted: July 8, 2011 doi:10.5539/ijb.v3n4p2

\begin{abstract}
A novel approach by utilizing soybean curd residue, to produce polysaccharide from the edible mushroom Pleurotus ostreatus (P. ostreatus) in solid-state culture, was developed. Firstly, the significant effect of fermented conditions on the production of $P$. ostreatus polysaccharide was screened out to be inoculum size, moisture content and $\mathrm{C} / \mathrm{N}$ ratio by using a single factor experiment. Secondly, the three factors were optimized using central composite design in response surface methodology. As a result, a quadratic model was found to fit for the production of $P$. ostreatus polysaccharide, and the optimal fermented condition was determined as following: inoculum size (11.79\%), moisture content (74.64\%) and $\mathrm{C} / \mathrm{N}$ ratio (12.77). A yield of $38.207 \pm 1.049 \mathrm{mg} / \mathrm{g}$ for polysaccharide was observed in verification experiment. Compared with unfermented soybean curd residue, total polyphnol, protein and various amino acid of fermented soybean curd residue were increased significantly. Therefore, a nutritious ecologic feed could be produced using fermented soybean curd residue.
\end{abstract}

Keywords: Soybean curd residue, Pleurotus ostreatus, Polysaccharide, Recyclable biomass 


\section{Introduction}

Soybean curd residue (SCR), a by-product of tofu, soymilk or soy protein manufacturing, is just discharged as agro-industrial waste with little market value because of its short shelf life (O'Toole, 1997). SCR of 0.7 million tons is disposed in Japan annually, mostly by incineration which has caused severe environmental pollution (S. Mizumoto et al., 2006). In fact, SCR, generally, contains high nutritive quality. Fresh wet SCR includes fat (3.6\%), starch and sugar (6.4\%), protein (4.8\%), fibre (3.3\%) and water (81\%) (Akihiro Ohno et al., 1996). 27\% protein and 53\% carbohydrate on a dry weight basis (Ma et al., 1997), Which has superior protein efficiency ratio, suggesting that it is a potential source of low cost vegetable protein for animal feed (Wang Jinbing et al., 2008; O'Toole, 1999). Several studies have recently investigated the use of SCR, including improving the functional properties of SCR protein by acid deamidation (Chan, W. M., Ma, C. Y, 1999), using Bacillus subtilis $B 2$ to improve the antioxidant activity of Chinese traditional fermented soybean curd residue (Y.P. Zhu et al., 2007), using SCR as nitrogen source for the solid-state fermentation of a microorganism (Hsieh \& Yang, 2004).

On the other hand, Pleurotus ostreeatus (P. ostreatus) is the third most important cultivated mushroom for food purposes and it constitutes an integral part of the normal human diet (R. Cohen et al., 2002). P. ostreatus is considered as valuable health foods since it is low calories, fats and essential fatty acids, as well as high in vegetable proteins, vitamins and minerals (Agrahar-Murugkar, D., Subbulakshmi, G, 2005; Sanmee et al., 2003). Levostatin, a cholesterol-lowering drug derived from P. ostreatus, and its analogues are reported to be the best therapeutic agents for correcting hypercholesterolemia (Endo, 1988). An ethanolic extract of P. ostreatus has in-vitro antioxidant activities. $P$. ostreatus extract was found to contain a perceptible amount of total phenols in addition to other constituents such as ascorbic acid, $\alpha$-tocopherol, $\beta$-carotene and flavonoid compounds (rutin and chrysin), all of which contributed to the observed antioxidant activity (T. Jayakumar et al., 2009).

Bioactive polysaccharides in mushrooms can often be extracted from mycelia of the species without waiting for a full fruiting body to develop (Song et al., 1998; Hatvani, 2001). Therefore, mycelial cultivation has received great interest as an efficient method for industrial production of valuable metabolites, and various agro-industrial by-products have been tried as inexpensive growth substrates (Hatvani, 2001; Fang Q., J. Zhong., 2002). In this study, P. ostreatus polysaccharide was the target substance from fermented SCR.

In recent years, solid-state cultivation (SSC) of mycelia has led to a wide range of applications at the laboratory scale because information from SSC can be applied to more commonly used liquid-state cultivation (Lekha, Lonsane, 1994). SSC has also been frequently utilized in preliminary tests for cultivating microorganisms under experimental conditions since it requires less time and less labor intensive than liquid-state cultivation (M. Song et al., 2007). Moreover, the fermented equipments are simple, the efficiency of the fermentation is high, there is no fermented waste liquid and eco-friendly.

In order to find out an optimum condition for producing $P$. ostreatus polysaccharides, response surface techniques are used in this study, because they are important statistical optimization methods which many factors can be optimized simultaneously and much quantitative information can be extracted by only a few experimental trials (Houng et al., 2003). There are a lot of successfully applied to the improvement of culture media or the production of primary and secondary metabolites in the cultivation process of many edible and medicinal mushrooms (Chang et al., 2006; Chen et al., 2008; Cui et al., 2006; Mao et al., 2005). However, there is still lack of knowledge concerning conditions of SSC for the production of $P$. ostreatus polysaccharides by statistical optimization techniques.

In this study, the objective of this research was to find out an optimum condition, which maximize quantity of $P$. ostreatus polysaccharides using SCR, as well as protein, total polyphenol and variety of amino acid of fermented SCR were detected to produce potential functional animal feed to substitute the antibiotic added to the feed, and improve the safety of food.

\section{Materials and methods}

\subsection{Microorganism and culture conditions}

P. ostreatus was obtained from agriculture and forestry strains Kaishas, Japan. D-glucose, sucrose, peptone, $\mathrm{KH}_{2} \mathrm{PO}_{4}, \mathrm{MgSO}_{4}$, potato extract, agar were obtained from Wako Pure Chemical, Osaka, Japan.

The strain was maintained on potato dextrose agar (PDA) at $4{ }^{\circ} \mathrm{C}$. To keep the strain activity, a mycelium square of size $5 \mathrm{~mm} \times 5 \mathrm{~mm}$ was transferred to a fresh PDA agar every 3 months. The activation medium (F.C.Yang, C.B.Liau, 1998) consisted of the following components: $2 \%$ glucose, $2 \%$ peptone, $0.4 \%$ potato extract, $0.3 \%$ $\mathrm{KH}_{2} \mathrm{PO}_{4}, 0.15 \% \mathrm{MgSO}_{4}, 2 \%$ agar. The initial $\mathrm{pH}$ was not adjusted (5.0 - 5.5). Mycelial agar petri dish was incubated at $25{ }^{\circ} \mathrm{C}$ for 7 days. The seed for solid culture was from liquid culture. The liquid culture was 
performed in $50 \mathrm{~mL}$ flask containing one unit of mycelia ager square, which was $5 \mathrm{~mm} \times 5 \mathrm{~mm}$ and obtained by a self-designed cutter. The flask liquid culture medium was composed of the following components: $2 \%$ sucrose, $2 \%$ yeast extract, $0.4 \%$ potato extract, $0.1 \% \mathrm{NaCl}, 0.3 \% \mathrm{KH}_{2} \mathrm{PO}_{4}, 0.15 \% \mathrm{MgSO}_{4}$. The initial $\mathrm{pH}$ was from 5.0 to 5.5 and was incubated on a rotary shaker at $100 \mathrm{rpm}$ and $25{ }^{\circ} \mathrm{C}$ for 6 days. Solid-state culture experiment was performed in $200 \mathrm{~mL}$ flask with wet SCR in different culture conditions and incubated at $25{ }^{\circ} \mathrm{C}$. All of the media were autoclaved at $121{ }^{\circ} \mathrm{C}$ for $20 \mathrm{~min}$.

\subsection{Polysaccharide determination}

The fermented SCR was dried in a bake oven at $50{ }^{\circ} \mathrm{C}$ and ground to powder. The crushed powder $(500 \mathrm{mg})$ was extracted with $80{ }^{\circ} \mathrm{C}$ hot water for two hours. The water-soluble polysaccharide was precipitated by adding eight volumes of $99.5 \%$ ethanol and stored at $4{ }^{\circ} \mathrm{C}$ overnight. The precipitated polysaccharide was collected by centrifuged at $7000 \times \mathrm{g}$ for $30 \mathrm{~min}$. Then the precipitate was dissolved in $10 \mathrm{~mL}$ distilled water. Total polysaccharide was determined by phenol-sulfuric acid method with some modifications. (M. Mauro, 2005; S.J. Rhee et al., 2008). The color reaction was initiated by mixing $1 \mathrm{~mL}$ of polysaccharide solution with $0.5 \mathrm{~mL}$ of $5 \%$ phenol solution and $2.5 \mathrm{~mL}$ of concentrated sulfuric acid, and the reaction mixture was kept in a $100{ }^{\circ} \mathrm{C}$ water bath for $15 \mathrm{~min}$. After cooling to room temperature, the optical density (OD) of the mixture was determined at $490 \mathrm{~nm}$ and the polysaccharide content was calculated with D-glucose as the standard. The results were expressed as mg of glucose equivalent per $\mathrm{g}$ of fermented SCR.

\subsection{Total polyphenol determination}

Total polyphenol content was determined using the Folin-Ciocalteu method with some modifications (J.L. Mau, et al., 2002; Singleton, Rossi, 1965). $200 \mathrm{mg}$ fermented SCR was mixed with $7.5 \mathrm{~mL}(80 \% \mathrm{~V} / \mathrm{V})$ alcohol and put on a rotary shaker at $100 \mathrm{rpm}$ at $25{ }^{\circ} \mathrm{C}$ for 24 hours. Then the supernatant was collected by centrifugation at $8000 \times \mathrm{g}$ for $20 \mathrm{~min}$. The supernatant $(0.125 \mathrm{~mL})$ was mixed with distilled water $(0.375 \mathrm{~mL}), 0.5 \mathrm{~mL}$ of the Folin-Ciocalteu reagent (Sigma, Saint Louis, MO, USA) respectively. Three minutes later, $0.5 \mathrm{~mL} \mathrm{Na}_{2} \mathrm{CO}_{3}(20 \%)$ was added, and the mixture was made up to $5 \mathrm{~mL}$ with distilled water. After being kept in the dark for $90 \mathrm{~min}$, the OD of the mixture was read at $725 \mathrm{~nm}$. The quantification was determined based on a standard curve of gallic acid $(25-250 \mu \mathrm{g} / \mathrm{mL})($ Sigma). Results were expressed as $\mathrm{mg}$ of gallic acid equivalent (GAE) per $\mathrm{g}$ of fermented SCR.

\subsection{Protein determination}

The protein content of fermented SCR was determined using the Protein Quantification Kit-Rapid (Wako Pure Chemical, Osaka) according to the manufacturer's instructions. Briefly, $200 \mathrm{mg}$ fermented SCR was mixed with $4 \mathrm{~mL}$ phosphate buffer ( $\mathrm{pH}:$ 7.6) and kept homogenate by pulp refiner for $2 \mathrm{~min}$. After $10 \mathrm{~min}, 6 \mu \mathrm{L}$ supernatant and $300 \mu \mathrm{L}$ Coomassie Brilliant Blue (CBB) were added into 96-well plate separately, then read the OD of the mixture at $595 \mathrm{~nm}$ and the protein content was calculated with BSA solution as the standard. The results were expressed as $\mathrm{mg}$ of protein per $\mathrm{g}$ of fermented SCR.

\subsection{Free amino acid determination}

The fermented SCR was extracted with $80 \%$ (V/V) ethanol in $80{ }^{\circ} \mathrm{C}$ water bath for 20 min. Recovered supernatant and repeated the previous steps twice. After washing solid matter with $80 \%$ (V/V) ethanol, centrifuged and filtered all the recovered supernatant. Totally dried the supernatant in bake oven at $40{ }^{\circ} \mathrm{C}$ and dissolved again with distilled water keeping at $4{ }^{\circ} \mathrm{C}$ for $12 \mathrm{~h}$. Mixed the solution with TCA solution at the ratio of $4: 1$ and placing at $4{ }^{\circ} \mathrm{C}$ for $10 \mathrm{~min}$ followed a centrifugation to remove the protein sediments. The $\mathrm{pH}$ value of mixture was adjusted to $2-3 \mathrm{using} \mathrm{NaOH}$ and $\mathrm{HCl}(1 \mathrm{~mol} / \mathrm{L})$, then centrifuged and filtered by $0.45 \mu \mathrm{m}$ diameter filter and determined by an auto amino acid analyzer (JLC-500/V2, Jeol Ltd., Tokyo, Japan) in accordance with the manufacturer's specifications.

\subsection{Optimization procedure and experimental design}

Response surface methodology was used to determine the influence of three independent variables and the optimum conditions of the production of $P$. ostreatus polysaccharide. The process variables and the responses were selected by single factor experiments. The effects of the variables inoculum size $\left(\mathrm{x}_{1}\right)$, moisture content $\left(\mathrm{x}_{2}\right)$, and carbon and nitrogen ratio $(\mathrm{C} / \mathrm{N})\left(\mathrm{x}_{3}\right)$ on the production of P.ostreatus polysaccharide using SCR were investigated. Each variable was coded at three levels: -1, 0, 1 (Table 1).

The variables were coded according to the following equation:

$$
x i=(X i-\overline{X i}) / \Delta \overline{X_{i}}
$$

where $\mathrm{xi}$ is the dimensionless value of an independent variable, $\mathrm{Xi}$ is the real value of an independent variable, 
$\overline{X i}$ is the real value of an independent variable at the center point, $\Delta \overline{X i}$ is the step change. The response function investigated was $\overline{Y i}=\mathrm{mg} P$. ostreatus polysaccharide/g fermented SCR. A central composite experimental design (CCD) was arranged to allow for fitting of second-order model (Nakai, S. et al., 2006) (Table 2). The star points were added to the factorial design to provide for estimation of curvature of the model. Five replicates at the center point of the design (runs13-17) were used to allow for estimation of the pure error sum of squares. All experiments were carried out in a randomized order to minimize any effect of extraneous factors on the observed responses.

The model proposed for response $\left(Y_{\mathrm{i}}\right)$ was:

$$
Y i=b_{0}+b_{1} x_{1}+b_{2} x_{2}+b_{3} x_{3}+b_{11} x_{1}^{2}+b_{22} x_{2}^{2}+b_{33} x_{3}^{2}+b_{12} x_{1} x_{2}+b_{13} x_{1} x_{3}+b_{23} x_{2} x_{3}
$$

where $Y i$ is predicted response, $b_{0}$ is offset term, $b_{1}, b_{2}$ and $b_{3}$ are linear effect terms, $b_{11}, b_{22}$ and $b_{33}$ are squared effects and $b_{12}, b_{13}$ and $b_{23}$ are interaction effects.

The significance of each coefficient was determined using the F-test and p-value. The corresponding variables would be more significant if the absolute F-value becomes greater and the p-value becomes smaller (Yi Song et al., 2010). All analyses were aided with Stat-Ease Design-Expert 8.0.5 (Stat-Ease Corporation, USA).

\section{Results and discussion}

\subsection{Screening of the signal factor for P.ostreatus polysaccharides}

Although single variable method was tedious, and overlook the interaction between different factors, this method was helpful for the selection of levels, making the result more reasonable and credible. Inoculum size had decided the growth of mycelium, when inoculum size was too little, the fermentation starting time was long. In contrast, more inoculum size caused the nutrition to be consumed quickly, and the fermentation could be stopped. Therefore, inoculum size needed to be suitable. Fig.1.A indicated that $10 \%$ (ratio of the mass) was the optimum inoculum size for the production of polysaccharide, with a maximum production of $29.5 \mathrm{mg} / \mathrm{g}$. More SCR did not show any positive effect on polysaccharide production.

The moisture content has an important role in SSC and although fermentation with relatively from no moisture to very high initial moisture levels have been reported (B.A. Prior, 1992), it has been observed that high moisture content leads to aggregation of substrate particles, poor aeration, and possible anaerobic conditions (R.P. Tengerdy, 1985). While very low moisture content restricts the fungal growth (P. Gervais, P. Molin, 2003). Optimal moisture content depends on the nature of microorganism and the substrate being used (Nikhil S et al, 2008). For the production of polysaccharide, $75 \%$ initial moisture was the optimum and maximum polysaccharide yield was $36.42 \mathrm{mg} / \mathrm{g}$ by $P$. ostreatus. Thereafter, polysaccharide yield was reduced with increasing moisture content (Fig.1.B).

In order to study the effect of initial $\mathrm{pH}$ values on the production of $P$. ostreatus polysaccharide, fermentation experiments were carried out at different initial $\mathrm{pH}$ values. The $\mathrm{pH}$ values were varied between $5.0 \pm 0.2$ and 7.0 \pm 0.2 with $0.5 \mathrm{~N}$ phosphate buffer. The effect of different $\mathrm{pH}$ on the production of polysaccharide in SSC was investigated and the result was shown in Fig.1.C. The study suggested that an initial $\mathrm{pH} 5.5$ was the optimum $\mathrm{pH}$ with a maximum polysaccharide production of $34.88 \mathrm{mg} / \mathrm{g}$. Further increasing in initial $\mathrm{pH}$ value led to decrease polysaccharide yield.

The $\mathrm{C} / \mathrm{N}$ ratio is found to be a crucial factor for the growth rate of mycelium and also for the content and the medical function of $P$. ostreatus polysaccharide (Chienyan et al., 2004). Therefore, it is important to adjust the $\mathrm{C} / \mathrm{N}$ ratio for the production of $P$. ostreatus polysaccharide. Total carbon and total nitrogen were $45.54 \%$ and $4.22 \%$ respectively in $\mathrm{SCR}$, thus $\mathrm{C} / \mathrm{N}$ ratio was 10.8 . Media with $\mathrm{C} / \mathrm{N}$ ratios ranged from 5 to 40 were packed in $200 \mathrm{~mL}$ flask to estimate the production of $P$. ostreatus polysaccharide (Fig.1.D). Sucrose and yeast extract were used to adjust the $\mathrm{C} / \mathrm{N}$ ratios. The yield of polysaccharide was changed a little between $\mathrm{C} / \mathrm{N}$ ratios of 5 and 10 . However, increasing $\mathrm{C} / \mathrm{N}$ ratios caused decline of polysaccharide, therefore, the yield of polysaccharide was decreased after $\mathrm{C} / \mathrm{N}$ ratio of 10 .

A time course of $P$. ostreatus polysaccharide production in SSC was presented in Fig.1.E. The result clearly showed that yield of polysaccharide was significantly affected by incubation time. Polysaccharide quickly increased up to about $36.75 \mathrm{mg} / \mathrm{g}$ on 20 days. After that, a gradual decrease trend of polysaccharide yield was observed.

\subsection{Paramenter of solid-state cultivation of P. ostreatus polysaccharides using surface analyses}

Based on the above result, further study was carried out by response surface methodology. Three variable (inoculum size, moisture content and $\mathrm{C} / \mathrm{N}$ ratio) were used to determine the optimum levels of these parameters 
and interactions according to fermented time 20 days and $\mathrm{pH}$ value 5.5. The design matrix of the variables in coded units is given in Table 1 . The replication at the centre point conditions resulted in higher polysaccharide yield than at other levels. The predicted response $\mathrm{Y}$ for the production of polysaccharide was obtained as follows:

$$
\begin{aligned}
& Y=-447.95+35.04 x_{1}+5.95 x_{2}+9.57 x_{3}+0.05 x_{1} x_{2} \\
& -0.61 x_{1} x_{3}+0.0004 x_{2} x_{3}-1.34 x_{1}^{2}-0.004 x_{2}^{2}-0.099 x_{3}^{2}
\end{aligned}
$$

The statistical significance of Eq. (3) was confirmed by an F-test, and the analysis of variance (ANOVA) for response surface quadratic model was summarized in Table 3.

The ANOVA of the quadratic regression model demonstrated that the model was significant, with an F-test of a very low probability value $(\mathrm{P}>\mathrm{F})<0.0001$. The goodness of the model was indicated by the determination coefficient $\left(R^{2}\right)$ and the multiple correlation coefficient $(R)$. The value of $R^{2}(0.8591)$ for Eq. (3) suggested that the sample variation of $85.91 \%$ for polysaccharide production was attributed to the independent variables. In addition, value of lack of fit $F$ value and lack of fit $p$-value were found to be 1.91 and 0.2692 , respectively, which implied that the lack of fit was insignificant relative to the pure error due to noise. Insignificant lack of fit made the model fit. The results suggested that the proposed experimental design was suitable for the simulation of polysaccharide production from $P$. ostreatus within the range of variables employed.

The interactions and optimal levels of the variables were determined by plotting the response surface curves. The shapes of the contour plots indicate whether the mutual interactions between the variables are significant or not. The circular contour plot of response surfaces suggests that the interaction is negligible between the corresponding variables, while an elliptical or saddle nature of the contour plot indicates that the interactions between the corresponding variables are significant (Muralidhar et al., 2001). The response surface curves were generated as shown in Fig. 2, which depicted the interactions between two variables by keeping the other variables at their zero levels for polysaccharide production. These 3D plots and their respective contour plots provided a visual interpretation of the interaction between two factors and facilitated the location of optimum experimental conditions. From the Eq. (3), the optimal values of $x_{1}, x_{2}$ and $x_{3}$ were estimated to be -0.164 , 0.469 and 0.424 , respectively. Correspondingly, their actual values were $11.79 \%$ inoculum size, $74.69 \%$ moisture content and $12.12 \mathrm{C} / \mathrm{N}$ ratio, respectively. The predicted maximum yield of polysaccharide was 38.207 $\mathrm{mg} / \mathrm{g}$ under the optimum condition, which was higher than the value of $33.2 \mathrm{mg} / \mathrm{g}$, that was showed in the paper of Haibin Tong et al. (Haibin Tong et al., 2009).

\subsection{The changes of other nutrients}

Table 4 showed the changes of nutrients between unfermented SCR and fermented SCR. Cultivated with the optimized conditions, the polysaccharide of fermented SCR $(37.942 \pm 1.049 \mathrm{mg} / \mathrm{g})$ was accumulated and as much as quadruple compared with unfermented SCR. Ethyl acetate and methanol extracts of $P$. ostreatus have been found to exhibit potent scavenging of hydroxyl radicals and inhibition of lipid peroxidation activities (Jose, Janardhanan, 2000). Especially, the most attractive property of $P$. ostreatus, polysaccharide has showed to exhibit hematological, antiviral, antitumor, antibiotic, antibacterial, hypocholesterolic and immunomodulation activities. (R. Cohen et al., 2002). The polyphenol is a good radical scavenger, which can eliminate the free radical of human, enhance immunity and has the anti-senile function. Moreover, the polyphenol effects on falling blood fats obviously. Table 4 suggested that total polyphenol of fermented SCR were $15.362 \mathrm{mg}$ GAE/g and six-fold contrasted with unfermented SCR. The protein of fermented SCR was $200.980 \mathrm{mg} / \mathrm{g}$ and twenty-fold compared with unfermented SCR (Table 4). Fermented SCR contained 20\% protein (dry matter) and the protein content of $1 \mathrm{~kg}$ fermented SCR was equal to the protein content of $2 \mathrm{~kg}$ lean meat, $3 \mathrm{~kg}$ the egg or $12 \mathrm{~kg}$ the milk content, as well as this protein surpassed the above products and was assimilated easily (Admin, 2010). Similar results had showed that incubation of stoned olive pomace, mixed $(25 \%, \mathrm{w} / \mathrm{w})$ with various conventional feedstuffs (i.e., wheat bran, wheat middlings, barley grains, crimson clover, wheat flour shorts and field beans), with Pleurotus ostreatus led to significant crude protein increases, ranging from 7 to 29\% (Viviana Brozzoli et al., 2010). For amino acid, serine, threonine, glycine, alanine, phenylalanine and gaba amino acid were increased remarkably and glutamine acid, methionine, isoleucine, leucine and tyrosine were emerged, especially, aspartic acid of fermented SCR was increased more than one hundred times compared with unfermented SCR. The aspartic acid has the widespread use in the medicine, food and chemical industry. In the medicine, it uses for treating heart disease, the liver complaint and hypertension sickness, it also can prevent and resume the weary function. In sum, the quantity and verities of active substances in SCR were raised obviously after fermentation. These indicated that the fermented SCR could be a potential and nutritious ecologic feed. 


\subsection{Evaluation of ecological advantage}

With the popular of bean products, the by-products, SCR is increased massively. The production of SCR reaches as high as 20 million tons in China, and also in Japan it is $0.7 \sim 0.8$ million tons every years. Because the moisture ratio of fresh SCR is excessively high, which is more than $80 \%$, it is acidifird easily and heavy stench to expose to the air without treatments. Therefore, it could cause severe environmental pollution. In Japan most SCR is incinerated or landfilled directly, and the disposal cost of SCR is 10,000 20,000 Japanese yen/ton. Although there were some reports about making SCR into the health food and feed, processing techniques were too complex and cost was too high to use widely (O'Toole, D. K., 1999, Pham, MA. et al., 2010). The production of ecologic feed by an edible mushroom is a new, simple and economic method to reuse SCR raw materials in SSC. With a high content of polysaccharide and polyphenol, make the feed having a high immunity and anti-inflammatory in order to instead the antibiotic and increasing the feed security.

SSC has gained a fresh attention in the recent years, mainly due to its advantages over submerged fermentation such as low capital investment, solid waste management, no waste liquid, no secondary pollution, reduced energy requirements, improved product recovery, etc (Shah, Madamwar, 2005; Singhania et al., 2009). SSC is a process whereby an insoluble substrate is fermented with sufficient moisture but without free water (Chahal, 1985). The substrates generally used are low cost agro- residues such as wheat straw, wheat bran, baggase, soya hulls etc., which further reduce the production cost (Mohana et al., 2008; Shah, Madamwar, 2005). Thus SSC is a fit way to produce ecologic feed reusing SCR. Moreover, it could be a wide range of promotion and use widely. After fermentation, not only flavour and mouthfeel but also the quantity and verities of bioactive substances were raised obviously in SCR. Especially, protein was increased twenty times contrasted with unfermented SCR.

In brief, reusing SCR to produce ecologic feed for SSC was not only simple, but also alleviation pressure on the environment. The fermented SCR was rich of nutrient substance and low cost, causing very good economic efficiency.

\section{Conclusions}

In conclusion, the production of $P$. ostreatus polysaccharide was obtained the maximum in these conditions: inoculum size of $10 \%$ (ratio of the mass), moisture content of $75 \%, \mathrm{pH}$ value of $5.5, \mathrm{C} / \mathrm{N}$ ratio of 10 and fermented time of 20 days. Response surface analysis revealed that the optimized culture condition for $P$. ostreatus polysaccharide production was inoculum size $(11.79 \%)$, moisture content $(74.69 \%)$ and $\mathrm{C} / \mathrm{N}$ ratio (12.12). Furthermore, total polyphenol, protein and various amino acide were increased significantly compared with unfermented SCR. These stated that the fermented SCR could be a potential and nutritious ecologic feed. Further works on the isolation, purification, characterization and functional effects of polysaccharide resuing SCR from P. ostreatus is in progress.

\section{References}

Admin. (2010). Protein, Amino Acid, Vitamin, Inorganic Salt of Edible Fungus. [Online] Available: http://www.guanxixue.com/a/ysyy/shiwuyingyang/2010/1124/343.htmL

Agrahar-Murugkar, D., Subbulakshmi, G. (2005). Nutritional value of edible wild mushrooms collected from the Khasi hills of Meghalaya. Food Chemistry. 89: 599-603. http://dx.doi.org/10.1016/j.foodchem.2004.03.042

B.A. Prior, J.C.D. Preez, P.W. Rein. (1992). Evironmental parameters, in: Solid Substrate Cultivation, Elsevier, London, p. 65.

Chahal, D.S. (1985). Solid state fermentation with Trichoderma reesei for cellulose production. Appl. Environ. Microbiol, 49: 205-210.

Chan, W.M., Ma, C.Y. (1999). Acid modification of proteins from soymilk residue (okara). Food Research International. 32: 119-127. http://dx.doi.org/10.1016/S0963-9969(99)00064-2

Chang, M. Y., Tsai, G. J., Houng, J. Y. (2006). Optimization of the medium composition for the submerged culture of Ganoderma lucidum by Taguchi array design and steepest ascent method. Enzyme and Microbial Technology, 38. 407-414. http://dx.doi.org/10.1016/j.enzmictec.2005.06.011

Chen, W., Zhao, Z., Chen, S. F., Li, Y. Q. (2008). Optimization for the production of exopolysaccharide from Fomes fomentarius in submerged culture and its antitumor effect in vitro. Bioresource Technology, 99: 3187-3194. http://dx.doi.org/10.1016/j.biortech.2007.05.049

Chienyan Hsieh, Fan-Chiang Yang. (2004). Reusing soy residue for the solid-state fermentation of Ganoderma lucidum. Bioresource Technology, 91: 105-109. http://dx.doi.org/10.1016/S0960-8524(03)00157-3 
Cui, F. J., Li, Y., Xu, Z. H., Xu, H. Y., Sun, K.,Tao, W. Y. (2006). Optimization of the medium composition for production of mycelial biomass and exo-polymer by Grifola frondosa GF9801 using response surface methodology. Bioresource Technology, 97: 1209-1216. http://dx.doi.org/10.1016/j.biortech.2005.05.005

Endo, A. (1988). Chemistry,biochemistry,and pharmacology of HMG-Co A reductase inhibitors. Klin Wochenschr, 66: 421-427. http://dx.doi.org/10.1007/BF01745510

F.C. Yang, C.B. Liau. (1998). The influence of environmental conditions on polysaccharide formation by Ganoderma lucidum in submerged culture. Process Biochem, 33: 547-553. http://dx.doi.org/10.1016/S0032-9592(98)00023-5

Fang Q., J. Zhong. (2002). Effect of initial pH on production of ganoderic acid and polysaccharide by submerged fermentation of Ganoderma lucidum. Process Biochem, 37: 769-774. http://dx.doi.org/10.1016/S0032-9592(01)00278-3

Haibin Tong, Fengguo Xia, Kai Feng, Guangren Sun, Xiaoxv Gao, Liwei Sun, Rui Jiang, Dan Tian, Xin Sun. (2009). Structural characterization and in vitro antitumor activity of a novel polysaccharide isolated from the fruiting bodies of Pleurotus ostreatus. Bioresource Technology, 100: 1682-1686. http://dx.doi.org/10.1016/j.biortech.2008.09.004

Hatvani, N. (2001). Antimicrobial effect of the culture $\ddot{\imath} \neg$, uid of Lentinus edodes mycelimgrown in submerged liquid culture. Int. J. Antimicrob. Agents, 17: 71-74. http://dx.doi.org/10.1016/S0924-8579(00)00311-3

Houng, J. Y., Hsu, H. F., Liu, Y. H., Wu, J. Y. (2003). Applying the Taguchi robust design to the optimization of the asymmetric reduction of ethyl 4-chloroacetoacetate by bakersâ тм yeast. Journal of Biotechnology, 100: 239-250. http://dx.doi.org/10.1016/S0168-1656(02)00179-7

Hsieh, C., Yang, F. C. (2004). Reusing soy residue for the solid-state fermentation of Ganoderma lucidum. Bioresource Technology, 91: 105-109. http://dx.doi.org/10.1016/S0960-8524(03)00157-3

J.L. Mau, H.C. Lin, S.F. Song. (2002). Antioxidant properties of several specialty mushrooms. Food Res. Int., 35: 519-526. http://dx.doi.org/10.1016/S0963-9969(01)00150-8

Jose, N., Janardhanan, K. K. (2000). Antioxidant and antitumour activity of Pleurotus $\ddot{\imath} \neg$,orida. Current Science, 79: 941-943.

LEKHA PK, LONSANE BK. (1994). Comparative titers, location and properties of tannin acyl hydrolase produced by Aspergillus niger PKL 104 in solid state, liquid surface and submerged fermentations. Process Biochem, 29(6): 497-503. http://dx.doi.org/10.1016/0032-9592(94)85019-4

M. Mauro. (2005). Estimation of total carbohydrate amount in environmental samples by the phenol-sulphuric acid method assisted by multivariate calibration. Chemometrics and Intelligent Laboratory Systems, 79: 84-90. http://dx.doi.org/10.1016/j.chemolab.2005.04.005

M. Song, N. Kim, S. Lee, S. Hwang. (2007). Use of Whey Permeate for Cultivating Ganoderma lucidum Mycelia. American Dairy Science Association, 90: 2141-2146.

Ma CY, Liu WS, Kwok KC, Kwok F. (1997). Isolation and characterization of proteins from soymilk residue (okara). Food Res Int, 29: 799-805. http://dx.doi.org/10.1016/0963-9969(95)00061-5

Mao, X. B., Eksriwong, T., Chauvatcharin, S., Zhong, J. J. (2005). Optimization of carbon source and carbon/nitrogen ratio for cordycepin production by submerged cultivation of medicinal mushroom Cordyceps militaris. Process Biochemistry, 40: 1667-1672. http://dx.doi.org/10.1016/j.procbio.2004.06.046

Mohana, S., Shah, A., Divecha, J., Madamwar, D. (2008). Xylanase production by Burkholderia sp. DMAX strain under solid state fermentation using distillery spent wash. Bioresour. Technol, 99: 7553-7564. http://dx.doi.org/10.1016/j.biortech.2008.02.009

Muralidhar, R. V., Chirumamila, R. R., Marchant, R., Nigam, P. (2001). A response surface approach for the comparison of lipase production by Candida cylindracea using two different carbon sources. Biochemical Engineering Journal, 9(1): 17-23. http://dx.doi.org/10.1016/S1369-703X(01)00117-6

Nikhil S. Shaligram, Sudheer Kumar Singh, Rekha S. Singhal, George Szakacs, Ashok Pandey. (2008). Compactin production in solid-state fermentation using orthogonal array method by P. brevicompactum. Biochemical Engineering Journal, 41: 295-300. http://dx.doi.org/10.1016/j.bej.2008.05.011

Oâ TMToole, D. K. (1999). Characteristics and use of okara, the soybean residue from soy milk production. Journal of Agricultural and Food Chemistry, 47: 363-371. 
P. Gervais, P.Molin. (2003). The role of water in solid-state fermentation. Biochem. Eng. J., 13: 85-101. http://dx.doi.org/10.1016/S1369-703X(02)00122-5

Pham, MA., Hwang, GD., Kim, YO., Seo, JY., Lee, SM. (2010). Soybean meal and wheat flour, proper dietary protein sources for optimal growth of snail (Semisulcospira coreana). AQUACULTURE INTERNATIONAL, 18(5): 883-895. http://dx.doi.org/10.1007/s10499-009-9308-9

R. Cohen, L. Persky, Y. Hadar. (2002). Biotechnological applications and potential of wood-degrading mushrooms of the genus Pleurotus. Appl Microbiol Biotechnol, 58: 582-594. http://dx.doi.org/10.1007/s00253-002-0930-y

R.P. Tengerdy. (1985). Solid substrate fermentation, Trends Biotechnol, 3: 96-99. http://dx.doi.org/10.1016/0167-7799(85)90092-7

S. Mizumoto, M. Hirai, M. Shoda. (2006). Production of lipopeptide antibiotic iturin A using soybean curd residue cultivated with Bacillus subtilis in solid-state fermentation. Biotechnological Products and Process Engineering, 72: 869-875.

S.J. Rhee, S.Y. Cho, K.M. Kim, D.S. Cha, H.J. Park. (2008). A comparative study of analytical methods for alkali-soluble $\hat{I}^{2}$-glucan in medicinal mushroom, Chaga (Inonotus obliquus). LWT-Food Sci. Technol., 41: 545-549.

Sanmee, R., Dell, B., Lumyong, P., Izumori, K.,Lumyong, S. (2003). Nutritive value of popular wild edible mushrooms from northern Thailand. Food Chemistry, 84: 527-532. http://dx.doi.org/10.1016/S0308-8146(02)00595-2

Shah, A.R., Madamwar, D. (2005). Xylanase production under solid-state fermentation and its characterization by an isolated strain of Aspergillus foetidus in India. World J. Microbiol Biotechnol, 21: 233-243. http://dx.doi.org/10.1007/s11274-004-3622-1

Singhania, R.R., Patel, A.K., Soccol, C.R., Pandey, A. (2009). Recent advances in solid-state fermentation. Biochem. Eng. J., 44: 13-18. http://dx.doi.org/10.1016/j.bej.2008.10.019

Song, C. H., Y. J. Jeon, B. K. Yang, K. S. Ra,H. I. Kim. (1998). Anticomplementary activity of endo-sulphuric acid method assisted by multivariate calibration. Chemometrics and intelligent laboratory systems, 79: 84-90.

T. Jayakumar, P.A. Thomas, P. Geraldine. (2009). In-vitro antioxidant activities of an ethanolic extract of the oyster mushroom, Pleurotus ostreatus. Innovative Food Science and Emerging Technologies, 10: 228-234. http://dx.doi.org/10.1016/j.ifset.2008.07.002

Viviana Brozzoli et al. (2010). Stoned olive pomace fermentation with Pleurotus species and its evaluation as a possible animal feed. Enzyme and Microbial Technology, 46: 223-228. http://dx.doi.org/10.1016/j.enzmictec.2009.09.008

Wang Jinbing, Ma Haile, Duan Yuqing, Li Weng. (2008). Screening Test of Producing High Quality Protein Feedstuff Strains from Soybean Meal by Solid Fermentation. Journal of Anhui Agri.Sic., 36(19): 8112-8114.

Y.P. Zhu, J.F. Fan, Y.Q. Cheng, L.T. Li. (2007). Improvement of the antioxidant activity of Chinese traditional fermented okara (Meitauza) using Bacillus subtilis B2. Food Control, 19: 654-661. http://dx.doi.org/10.1016/j.foodcont.2007.07.009

Yi Song, Bingjian Du, Ting Zhou, Bing Han, Fei Yu, Rui Yang, Xiaosong Hu, Yuanying Ni, Quanhong Li. (2010). Optimization of extraction process by response surface methodology and preliminary structural analysis of polysaccharides from defatted peanut (Arachis hypogaea) cakes. Carbohydrate Research, 346: 305-310. http://dx.doi.org/10.1016/j.carres.2010.11.019

Table 1. Independent variable values of the process and their corresponding levels

\begin{tabular}{lccccccc}
\hline Independent variable & \multicolumn{2}{c}{ Symbol } & & \multicolumn{3}{c}{ Coded variables levels } \\
\cline { 2 - 3 } \cline { 6 - 8 } & Uncodified & Codified & & -1 & 0 & 1 \\
\hline Inoculum size (\%) & $X_{1}$ & $\mathrm{x}_{1}$ & & 10 & 12.5 & 15 \\
moisture content $(\%)$ & $X_{2}$ & $\mathrm{x}_{2}$ & & 60 & 70 & 80 \\
$\mathrm{C} / \mathrm{N}$ ratio & $X_{3}$ & $\mathrm{x}_{3}$ & & 5 & 10 & 15 \\
\hline
\end{tabular}


Table 2. CCD arrangement, responses and predicted values for polysaccharides content

\begin{tabular}{|c|c|c|c|c|c|c|c|c|c|}
\hline \multirow[t]{2}{*}{ Run } & \multicolumn{3}{|c|}{ Coded variables $^{\mathrm{a}}$} & \multicolumn{3}{|c|}{ Uncoded variables } & \multicolumn{3}{|c|}{ Polysaccharides content $(Y)(\mathrm{mg} / \mathrm{g})$} \\
\hline & $\mathrm{X}_{1}$ & $\mathrm{X}_{2}$ & $\mathrm{X}_{3}$ & $\mathrm{x}_{1}$ & $\mathrm{x}_{2}$ & $\mathrm{x}_{3}$ & Experimental $\left(Y_{0}\right)$ & $\operatorname{Predicted}\left(Y_{\mathrm{i}}\right)$ & $Y_{0}-Y_{\mathrm{i}}$ \\
\hline 1 & -1 & -1 & 0 & 10 & 60 & 10 & 24.09 & 23.31 & 0.78 \\
\hline 2 & 1 & -1 & 0 & 15 & 60 & 10 & 17.14 & 16.45 & 0.69 \\
\hline 3 & -1 & 1 & 0 & 10 & 80 & 10 & 28.60 & 29.27 & -0.67 \\
\hline 4 & 1 & 1 & 0 & 15 & 80 & 10 & 26.83 & 27.60 & -0.77 \\
\hline 5 & -1 & 0 & -1 & 10 & 70 & 5 & 20.60 & 20.62 & -0.02 \\
\hline 6 & 1 & 0 & -1 & 15 & 70 & 5 & 31.55 & 31.47 & 0.08 \\
\hline 7 & -1 & 0 & 1 & 10 & 70 & 15 & 35.73 & 35.83 & -0.10 \\
\hline 8 & 0 & 0 & 1 & 12.5 & 70 & 15 & 34.57 & 34.50 & 0.06 \\
\hline 9 & 0 & -1 & -1 & 12.5 & 60 & 5 & 24.95 & 25.71 & -0.76 \\
\hline 10 & 0 & 1 & -1 & 12.5 & 80 & 5 & 35.00 & 33.30 & 1.69 \\
\hline 11 & 0 & -1 & 1 & 12.5 & 60 & 15 & 25.13 & 25.84 & -0.71 \\
\hline 12 & 0 & 1 & 1 & 12.5 & 80 & 15 & 35.10 & 34.98 & 0.12 \\
\hline 13 & 0 & 0 & 0 & 12.5 & 70 & 10 & 37.40 & 36.93 & 0.47 \\
\hline 14 & 0 & 0 & 0 & 12.5 & 70 & 10 & 38.13 & 36.93 & 1.20 \\
\hline 15 & 0 & 0 & 0 & 12.5 & 70 & 10 & 36.50 & 36.93 & -0.43 \\
\hline 16 & 0 & 0 & 0 & 12.5 & 70 & 10 & 36.70 & 36.93 & -0.23 \\
\hline 17 & 0 & 0 & 0 & 12.5 & 70 & 10 & 35.89 & 36.93 & -1.04 \\
\hline
\end{tabular}

Table 3. Analysis of variance (ANOVA) for the regression equation

\begin{tabular}{cccccc}
\hline SD & DF & SS & F value & Prob $>$ F & S \\
\hline Model & 9 & 681.02 & 73.38 & $<0.0001$ & $* *$ \\
$X_{1}$ & 1 & 25.58 & 24.81 & 0.0016 & $* *$ \\
$X_{2}$ & 1 & 146.43 & 142.00 & $<0.0001$ & $* *$ \\
$X_{2}$ & 1 & 0.014 & 0.013 & 0.9109 & \\
$X_{1},{ }_{2}$ & 1 & 6.7 & 6.50 & 0.0381 & $*$ \\
$X_{1} X_{2}$ & 1 & 123.86 & 120.12 & $<0.0001$ & $* *$ \\
$X_{2} X_{2}$ & 1 & 0.0016 & 0.0015 & 0.9697 & \\
$X_{1}^{2}$ & 1 & 223.4 & 226.34 & $<0.0001$ & $* *$ \\
$X_{2}^{2}$ & 1 & 73.25 & 71.04 & $<0.0001$ & $* *$ \\
$X_{2}^{2}$ & 1 & 23.77 & 23.05 & 0.002 & $* *$ \\
Lack of fit & 3 & 4.25 & 1.91 & 0.2692 & \\
\hline
\end{tabular}

$\mathrm{R}^{2}$ (predict) $=0.8591 ; \mathrm{R}^{2}$ (adjust) $=0.9760 .{ }^{*} p<0.05,{ }^{* *} p<0.01$

SD: sources of deviation; DF: degree of freedom; SS: sum of squares; S: significant

Table 4. The nutrients change on unfermented SCR and fermented SCR

\begin{tabular}{rlll}
\hline & & Unfermented SCR & Fermented SCR \\
\hline & Serine & $0.660 \pm 0.012$ & $3.462 \pm 0.143$ \\
& Aspartic acid & $0.787 \pm 0.0231$ & $84.772 \pm 6.341$ \\
Amino acid & Threonine & $0.519 \pm 0.0162$ & $4.678 \pm 0.424$ \\
$(\mathrm{nmol} / \mathrm{mL})$ & Glycine & $1.539 \pm 0.164$ & $2.012 \pm 0.077$ \\
& Alanine & $10.883 \pm 0.862$ & $15.145 \pm 0.64$ \\
& Phenylalanine & $0.780 \pm 0.0131$ & $5.686 \pm 0.439$ \\
& Gaba amino acid & $1.436 \pm 0.021$ & $3.430 \pm 0.089$ \\
Polysaccharide (mg/g) & $8.004 \pm 0.539$ & $38.204 \pm 1.049$ \\
Total polyphenol (mg GEA/g) & $3.116 \pm 0.016$ & $15.362 \pm 0.044$ \\
Protein $(\mathrm{mg} / \mathrm{g})$ & $11.149 \pm 0.556$ & $200.980 \pm 7.05$ \\
\hline
\end{tabular}



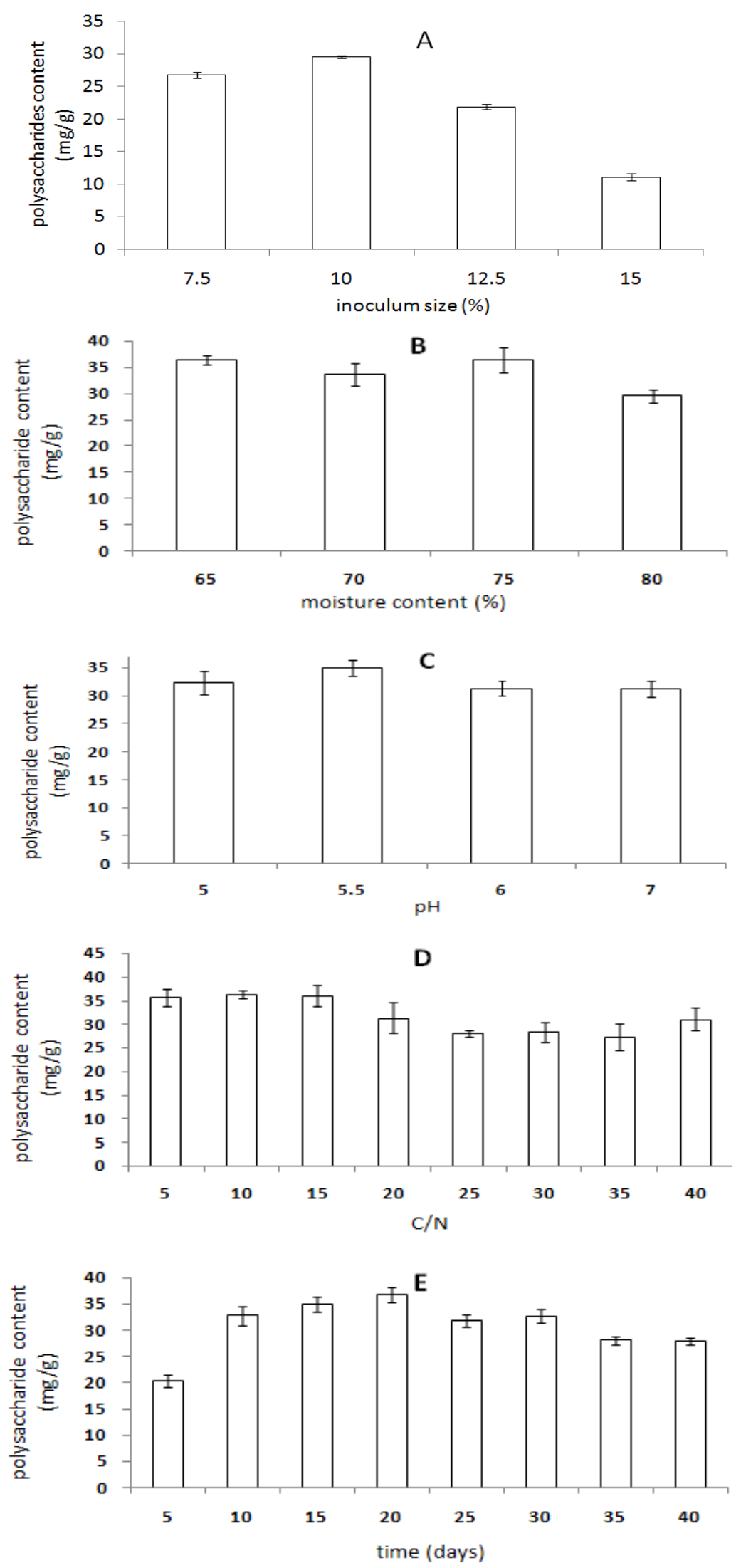

Figure 1. The production of polysaccharide in different single factor experiments.Inoculum size (A); Moisture content (B); $\mathrm{pH}$ value (C); $\mathrm{C} / \mathrm{N}$ ratio (D); Fermented time (E).The bars designate standard deviations (95\% confidence, t-test) 

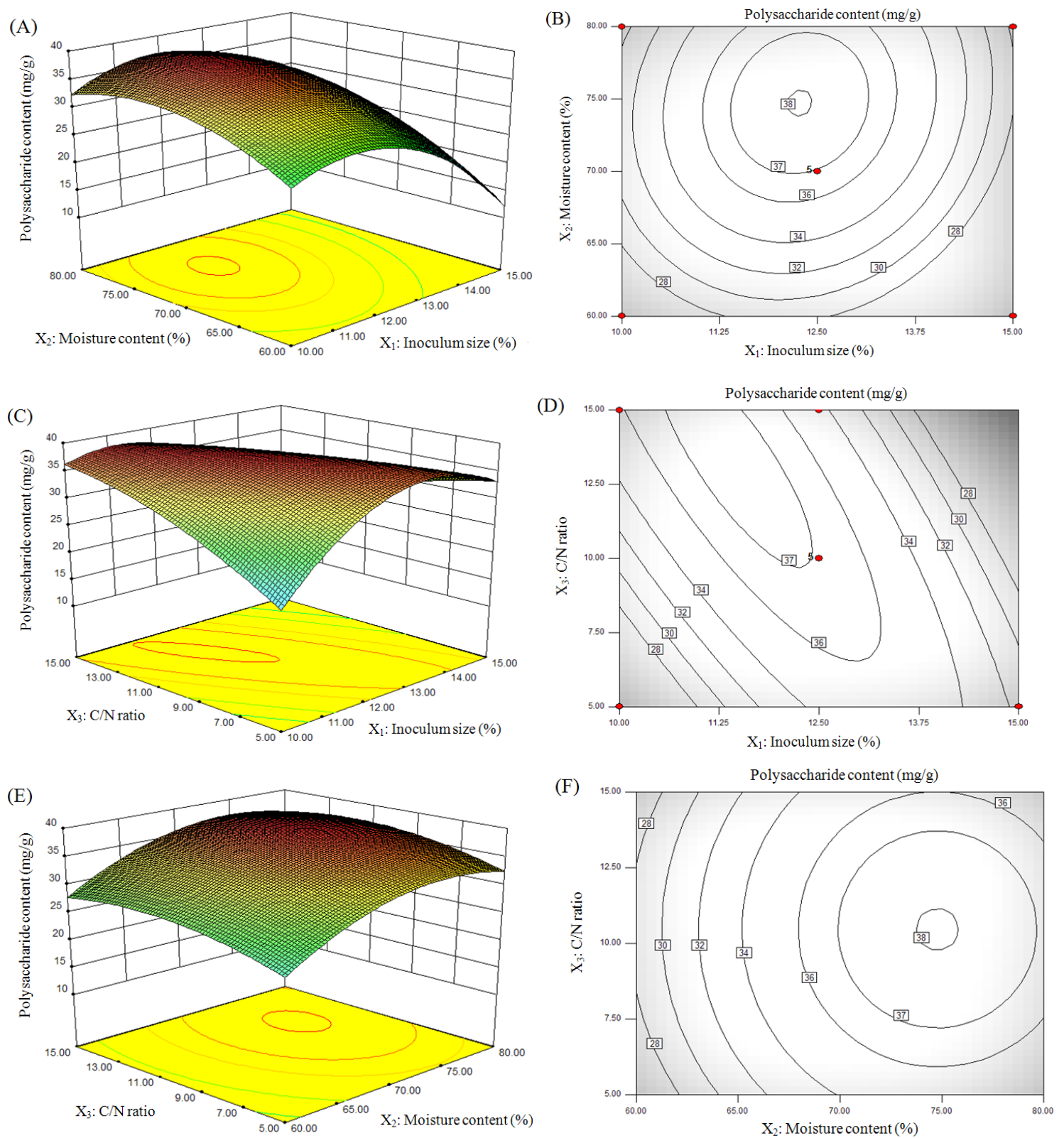

Figure 2. Response surface plots (A, C, E) and contour plots (B, D, F) showing the effects of quantity of soybean curd residue, moisture content and $\mathrm{C} / \mathrm{N}$ ratio on the yield of P.ostreatus polysaccharide 